\title{
Polikistik Over Sendromunda Hirsutizm Tedavisi İçin Dienogest veya Drospirenon İçeren İki Farklı Oral Kontraseptifin Karşılaştırıldığı Prospektif Randomize Bir Çalışma
}

\author{
Mustafa Taş(1)
}

Acıbadem Mehmet Ali Aydınlar Üniversitesi, Acıbadem Kayseri Hastanesi, Kadın Hastalıkları ve Doğum Bölümü, Kayseri, Türkiye

Mustafa Taş, Dr. Öğr. Üyesi

İletişim:

Dr. Öğr. Üyesi Mustafa Taş

Acıbadem Mehmet Ali Aydınlar Üniversitesi, Acıbadem Kayseri Hastanesi, Kadın Hastalıkları ve Doğum Bölümü, Kayseri, Türkiye Tel: +905355802318

E-Posta:drmustafatas@yahoo.com
ÖZET

Amaç: Polikistik over sendromlu kadınlarda hirsutizm tedavisinde drospirenon ve dienogest içeren iki oral kontraseptifin klinik etkinliğini karşılaştırmak için prospektif randomize bir çalışma yapııldı.

Hastalar ve Yöntem: Bu çalışmaya orta-şiddetli hirsutizm tanısı olan 50 kadın alındı. Yirmi beş hastaya 6 ay boyunca oral 0,03 mg etinil estradiol ve $3 \mathrm{mg}$ drospirenon 21/7 (Grup 1) verildi. 25 hastalık bir başka gruba 6 ay boyunca oral $0,03 \mathrm{mg}$ etinil estradiol ve $2 \mathrm{mg}$ dienogest 21/7 (Grup 2) verildi. Hirsutizm, 6 ay sonra Ferriman-Gallwey (FG) puanlama sistemi kullanılarak değerlendirildi. Her iki tedavinin de 6 ayının sonrasında görülen hormonal seviyeler bazal değerlerle ve birbirleriyle karşılaştıııldı.

Bulgular: Hirsutizm için F-G skorlarında (ortalama \pm SD) Grup 1'de $\left(19,3 \pm 6,2^{\prime}\right.$ den $\left.9,7 \pm 3,5^{\prime} y e, p<0,001\right)$ ve Grup 2'de $\left(19,5 \pm 5,8^{\prime}\right.$ den $\left.8,9 \pm 3,8^{\prime} \mathrm{e}, \mathrm{p}<0,001\right)$ bir iyileşme gözlenmiş̧ir. Tedavi öncesi ve sonrası hirsutizm skorları gruplar arasında karşılaştırılabilir olmuştur. Her iki grupta da tedaviden sonra toplam ve serbest testosteron düzeyleri anlamlı olarak azalmıştır. Cinsiyet hormonu bağlayııı globulin düzeyleri, 6 aylık dönemde her iki grupta da anlamlı olarak artmıştır.

Sonuç: Hirsutizmin, hem drospirenon hem de dienogest içeren kombine oral kontraseptiflerle (KOK) tedavisi, herhangi bir yan etkisi olmadan kıyaslanabilir etkilere sahiptir.

Anahtar sözcükler: Drospirenone, dienogest, hirsutizm, kombine oral kontraseptifler

A PROSPECTIVE RANDOMIZED TRIAL COMPARING TWO DIFFERENT ORAL CONTRACEPTIVES CONTAINING DIENOGEST OR DROSPIRENONE FOR THE TREATMENT OF HIRSUTISM IN POLYCYSTIC OVARIAN SYNDROME.

\section{ABSTRACT}

Objectives: A prospective randomized trial was conducted to compare the clinical efficacy of two oral contraceptives containing drospirenone and dienogest in the treatment of hirsutism in women with polycystic ovarian syndrome.

Patients and Methods: Fifty women with moderate to severe hirsutism were recruited into this study. Twenty-five patients received oral $0.03 \mathrm{mg}$ ethinyl estradiol and $3 \mathrm{mg}$ drospirenone 21/7 regimen (Group 1) for 6 months. Another group of 25 patients received oral $0.03 \mathrm{mg}$ ethinyl estradiol and $2 \mathrm{mg}$ dienogest 21/7 regimen (Group 2) for 6 months. Hirsutism was assessed after 6 months using the Ferriman-Gallwey (F-G) scoring system. Hormonal levels after 6 months of both therapies were compared with the baseline values and each other.

Results: An improvement in the F-G scores for hirsutism (mean \pm SD) was observed in Group $1(19.3 \pm 6.2$ to $9.7 \pm 3.5, p<.001)$ and in Group $2(19.5 \pm 5.8$ to $8.9 \pm 3.8, p<.001)$. Pre- and post-treatment hirsutism scores were comparable between the groups. Total and free testosterone levels decreased significantly after the therapy in both groups. The sex hormone-binding globulin levels increased significantly in both groups during the 6-month period.

Conclusions: The treatment of hirsutism with both combined oral contraceptives (COCs) containing drospirenone and dienogest have comparable effects without any side effect.

Keywords: Drospirenone, dienogest, hirsutism, combined oral contraceptives
Gönderilme Tarihi : 16 Eylül 2019

Revizyon Tarihi : 16 Eylül 2019

Kabul Tarihi : : 29 Eylül 2019 
H irsutizm androjene bağımlı cinsel kılların aşırı büyümesi olarak tanımlanmaktadır (1). Kadın üreme çağındaki nüfusun \%5-8'i hirsutizmden etkilenmiştir (2). Hirsutizm kozmetik bir sorundur ve ayn zamanda psikolojik sıkıntılara da yol açar. Aşırı androjen üretimi veya androjenlerin potansiyelini artırma, hirsutizme neden olabilir (3). Hirsutizmli kadınlarda birinci aşama tedavisi kombine oral kontraseptiflerdir (KOK) (4). KOK, luteinize edici hormon (LH) salgılanmasını inhibe ederek, yumurtalıkta testosteron ( $\mathrm{T}$ ) üretiminin azalmasına neden olur. KOK'lerin östrojenik bileşeni, seks hormonu bağlayıc globulin (SHBG) sentezini artırması nedeniyle plazma T seviyelerinin androjenik etkilerini azaltır (5). Drospirenon, antiandrojenik etkiye sahip olan bir spironolakton analoğudur (6). Farmakolojik profili diğer progestinlere kıyasla doğal progesteronunkine daha çok benzemektedir (7). Etinil estradiol ve drospirenon kombinasyonu, güvenlik profili ile akne ve sebore için faydalı özelliklere sahiptir $(8,9)$. Polikistik over sendromu olan ve olmayan hastaların karşılaştırıldığı iki çalışmada bu tedavinin hirsutizm tedavisinde etkili olduğu gösterilmiştir (PCOS) (10). Yakın zamanda yapılan bir çalışmada, bu tedavinin hirsutizm üzerinde olumlu etkileri olduğu, PCOS'lu kadınlarda lipit, glisemik ve hormonal profil üzerinde KOK içeren desogestrele kıyasla daha iyi sonuçlarının olduğu gösterilmiştir (11). Klormadinon asetat, siproteron asetat ve dienogest dahil diğer antiandrojenik ilaçlar güçlü, oral olarak aktif antiandrojenik progestojenlerdir (12). Esas olarak hedef organlardaki androjen reseptörlerini bloke ederek etki gösterirler, fakat aynı zamanda cildin 5 alfa redüktaz aktivitesini, testosteronun daha güçlü androjen 5alfa-dihidrotestosterona dönüştürülmesinden sorumlu olan enzimi, yağ bezlerinde ve saç köklerinde azaltırlar $(13,14)$.

Bu çalışmanın amacı, polikistik over sendromlu (PCOS) kadınlarda aynı östrojen ve farklı progesteron içeren iki KOK ile klinik ve biyokimyasal sonuçlarımızı sunmaktır. Bilgimiz dahilinde PCOS'lu hirsutizm hastalarında bu iki KOK'i karşılaştıran bir çalışma yapılmamıştır.

\section{Materyal ve metod}

Bu prospektif randomize klinik çalışma, Acıbadem Mehmet Ali Aydınlar Üniversitesi Etik Kurulu'ndan (2016-7/15) etik onay alındıktan sonra Acıbadem Kayseri Hastanesinde orta ve şiddetli hirsutizmi olan 50 kişilik bir örneklem üzerinde gerçekleştirilmiştir.

Uygun katılımcılar; gebe olmayan, androjen salgılayan adrenal veya over neoplazmı kanıtı olmayan, Cushing sendromu, konjenital adrenal hiperplazi veya virilizasyon belirtileri olmayan premenopozal kadınlardı. Hirsutizm belirtilerine ek olarak, sonografide tipik yumurtalık görünümleri olan (genişletilmiş bir hiperekojenik merkezi stroma ile veya bu olmadan oniki veya daha fazla periferik olarak düzenlenmiş ayrı follikül) hastalara PCOS tanısı kondu (15).

Adet tarihi ve tıbbi geçmiş de dahil olmak üzere ayrıntılı bir öykü alındı. Her hastaya hormon profiline ek olarak tam bir tıbbi muayene ve karaciğer ve böbrek fonksiyon analizleri yapıldı. Kayıttan önceki son 12 ay boyunca, bir KOK veya uzun süredir progestin de dahil olmak üzere herhangi bir ilaç alan kişiler hariç tutuldu. Gözlemciler arası hatayı önlemek için değerlendirmeleri tek bir araştırmacı (MT) yaptı. Hastalardan tedavi sırasında epilasyon yapmamaları istendi. Dokuz vücut bölgesi saç büyümesinin yoğunluğu ve alanı için değerlendirildi ve 0-puan (hirsutizm yok) ile 4-puan (şiddetli) aralığında bir skala kullanıldı. Çalışmaya 8 veya daha fazla puan alan hastalar dahil edildi. Vücut kitle indeksi (VKI) şu formüle göre hesaplandı: "kilogram cinsinden vücut ağırlığı/metre kare cinsinden yüksekliğin karesi" ve hastalardan çalışma sırasında normal diyetlerini değiştirmemeleri istendi.

Bilgilendirilmiş onam alındıktan sonra, katılımcılar bilgisayar tarafından oluşturulan randomizasyon tablosu kullanılarak iki gruba randomize edildi. Grup 1'e $(n=25)$, günlük bir 0,03 mg etinil estradiol artı 21/7 günlük bir rejim olarak 3 mg drospirenon kombinasyonu (Yasmin ${ }^{\circledR}$ ) ve Grup 2'ye ( $n=25), 6$ ay boyunca 21/7 günlük bir rejim halinde günlük 0,02 mg etinil estradiol artı 3 mg drospirenon kombinasyonu (Dienelle ${ }^{\circledR}$ ) verildi.

Hastalar tedavi süresince 6 ay takip edildi. Hormon analizi için düzenli adet döngüsü olan kadınlarda erken folliküler fazda tedaviden önce veya amenoreik olanlar için uygun bir günde serum örnekleri alındı. Altı aylık tedavinin sonunda, bir önceki siklusun çekilme kanamasından sonraki 3. ve 6 . gün arasında kan örnekleri alındı. Tedavi sırasında, menstrüel siklusun sürecini ve yan etkileri belirlemek için hirsüt kadınların tamamı ile görüşüldü. Serum follikül uyarıcı hormon (FSH), total T, serbest $T$, androstenedion (A), östradiol (E2) (DSL-4900, Diagnostic Systems Laboratories, Webster, TX, ABD) ve DHEAS (Immunotech, Marseilles, Fransa) radyoimmunanaliz yöntemiyle, SHBG ise immunoradyometrik yöntem (Orion Diagnostica, Espoo, Finlandiya) ile ticari kitler kullanılarak biyokimya laboratuvarında ölçüldü.

Nümerik değişkenler ortalama \pm SS olarak belirtildi. Normal dağılıma sahip olmayan metrik değişkenler Kruskal-Wallis testi ve Mann-Whitney $U$ testi ile analiz edildiler. Normal dağılımın doğrulanmasının ardından, araştırma altındaki 
kadınların tedavi öncesi ve sonrasındaki değerlerini karşılaştırmak için bağımlı ve bağımsız t testleri kullanıldı. $\mathrm{P} \leq 0,05$ istatistik olarak anlamlı kabul edildi.

\section{Bulgular}

Kadınların tamamı araştırmayı tamamladı ve sonuçları rapor edildi. Hastaların hiçbiri KOK kullanımı sırasında tedavinin durdurulmasına sebep olacak büyüklükte bir şikayet veya yan etki belirtmediler. 1. ve 2. gruplardaki Hastaların VKi'leri (ortalama \pm SS) $(25,6 \pm 3,7$ 'ya karşın $24,9 \pm 5,6)$ ve yaşları $(25,6 \pm 4,4$ 'ya karşın $26,2 \pm 4,5)$ benzer seviyelerdeydi. Tedavilerin sonunda, grup içinde veya gruplar arasında VKi açısından anlamlı bir değişiklik gözlemlenmedi $(25,2 \pm 4,2$ 'ye karşılık $25,4 \pm 4,6)$. Tedavi öncesinde kadınların tamamı oligo/amenore durumuna sahip iken tedavi sonrasında iki gruptaki hastaların da siklüsleri düzenli hale geldi. Tablo 1, Altı aylık tedavinin öncesinde ve sonrasında 1. ve 2. gruplardaki hormon seviyelerini ve hirsutizm skorlarını göstermektedir. Ortalama F-G hirsutizm skoru açısından birinci grupta $\left(19,3 \pm 6,2^{\prime}\right.$ den $9,7 \pm 3,5^{\prime}$ e, $\left.p<0,001\right)$ ve ikinci grupta $\left(19,5 \pm 5,8^{\prime}\right.$ den $\left.8,9 \pm 3,8^{\prime} \mathrm{e}, \mathrm{p}<0,001\right)$ iyileşme gözlemlenmiştir. Tedavi öncesi ve 6 ayın sonundaki hirsutizm skorları kıyaslanabilir seviyede idi $(p<0,05)$. iki gruptaki ortalama FSH, LH, E2, A ve DHEAS seviyeleri arasında anlamlı bir farklılık yoktu. Buna ek olarak, tedavi sonrasında iki grupta da bu hormonların seviyesinde bir değişiklik gözlemlenmedi. Total ve serbest ortalama T seviyeleri iki grupta da tedavi sonrasında önemli ölçüde azalsa da iki grup arasında istatistiksel olarak anlamlı bir fark yoktu. Ortalama SHBG seviyeleri 6 aylık dönemin sonunda iki grupta da bazal seviyelere göre anlamlı olarak artmıştı $(p<0,05)$ (Tablo 1).

\section{Tartışma}

Drospirenon ve dienogest iki antiandrojenik progestandırlar ve çoğunlukla KOK olarak kullanılırlar. Özellikle dienogest, endometriyum üzerindeki güçlü progesteron etkisinden dolayı endometriyozis tedavisinde kullanılır (16). Ayrıca, drospirenon PCOS'da hirsutizm tedavisinde oldukça yaygın olarak kullanılmaktadır. Bu araştırma, literatürde iki farklı antiandrojenik progestan olan dienogest ile drospirenonun PCOS'lu kadınlarda hirsutizmin üzerindeki etkisini doğrudan karşılaştıran ilk randomize araştırmadır.

Literatürde, dienogestin antiandrojenik etkisini inceleyen yalnızca bir ön çalışma bulunmuştur (17). Bu araştırmaya göre dienogest, PCOS'lu kadınların akne semptomlarını $\% 52,8$ iyileştirmekte ve testosteron seviyelerini düşüren SHBG'nin seviyesini artırmaktadır. Drospirenonun SHBG seviyelerinde yüksek etinil östradiol miktarına yol açan antiandrojenik etkisi, aktif serbest $T$ miktarının azalması ile ilişkilidir (8). Bu sebeple, SHBG artışı iki tedavi rejiminin de antiandrojenik etkisinin temel faktörüdür. Araştırmamızda, iki grupta da SHBG seviyelerinin yükseldiği ve bu yükselişin PCOS'lu kadınlarda hirsutizm üzerinde olumlu bir etkiye sahip olduğu görülmüştür.

Yeni bir progestojen olan drospirenonu içeren KOK'lar klinik ve hormonal profiller bakımından daha iyi sonuçlara ulaşmakla beraber PCOS hastaları tarafından iyi tolere edilmişlerdir. Drospirenon-artı-etinilestradiol kombinasyonu hirsutizm skorunu iyileştirmede siproteron asetatartı-etinilestradiol kombinasyonu kadar etkili olmakla beraber istatistiksel olarak anlamlı bir yan etkisine de rastlanmamıştır (18). Bir başka çok merkezli araştırmada

Tablo 1. Tedavinin her iki grupta hormon profili ve hirsutizm üzerine etkileri

\begin{tabular}{|c|c|c|c|c|}
\hline & \multicolumn{2}{|c|}{ Bazal } & \multicolumn{2}{|c|}{ 6ay } \\
\hline & $\begin{array}{c}\text { Grup } 1 \\
(n=25)\end{array}$ & $\begin{array}{c}\text { Grup } 2 \\
(n=25)\end{array}$ & $\begin{array}{c}\text { Grup } 1 \\
(n=25)\end{array}$ & $\begin{array}{c}\text { Grup 2 } \\
(n=25)\end{array}$ \\
\hline FSH (mlU/mL) & $6,8 \pm 1,2^{a}$ & $6,8 \pm 1,7 a$ & $5,1 \pm 1,7^{\mathrm{a}}$ & $5,1 \pm 1,8^{\mathrm{a}}$ \\
\hline $\mathrm{LH}(\mathrm{mlU} / \mathrm{mL})$ & $10,9 \pm 0,4^{\mathrm{a}}$ & $10,8 \pm 0,4^{a}$ & $7,0 \pm 0,3^{b}$ & $6,9 \pm 0,3^{b}$ \\
\hline E2 (pg/mL) & $69,6 \pm 11,0^{a}$ & $69,4 \pm 11,4^{a}$ & $69,1 \pm 9,8^{\mathrm{a}}$ & $69,1 \pm 10,4^{\mathrm{a}}$ \\
\hline SHBG (nmol/L) & $43,3 \pm 22,1^{a}$ & $46,1 \pm 30,2^{\mathrm{a}}$ & $64,8 \pm 30,9^{b}$ & $72,1 \pm 58,6^{b}$ \\
\hline DHEAS $(\mu \mathrm{g} / \mathrm{mL})$ & $2,7 \pm 1,3^{\mathrm{a}}$ & $2,7 \pm 1,3^{\mathrm{a}}$ & $2,7 \pm 2,0^{a}$ & $2,7 \pm 1,4^{a}$ \\
\hline $\mathrm{A}(\mathrm{ng} / \mathrm{mL})$ & $2,8 \pm 0,3^{a}$ & $2,9 \pm 0,1^{\mathrm{a}}$ & $2,9 \pm 0,2^{\mathrm{a}}$ & $3,0 \pm 0,3^{a}$ \\
\hline Total T (ng/dL) & $88,5 \pm 43,7^{\mathrm{a}}$ & $87,5 \pm 40,5^{a}$ & $55,7 \pm 22,8^{b}$ & $56,0 \pm 36,4^{b}$ \\
\hline Free T (pg/mL) & $3,1 \pm 0,9^{a}$ & $2,9 \pm 0,7^{a}$ & $2,0 \pm 0,5^{b}$ & $2,0 \pm 0,8^{b}$ \\
\hline Hirsutizm puanı & $19,3 \pm 5,2^{\mathrm{a}}$ & $19,5 \pm 4,8^{a}$ & $9,7 \pm 2,5^{b}$ & $8,9 \pm 2,8^{b}$ \\
\hline
\end{tabular}

Not: Değerler ortalama \pm SS olarak verilmiştir. FSH: follikül uyarısı hormon, LH: luteinizan hormon, E2: estradiol, SHBG: seks hormonu bağlayıcı globulin,

DHEAS: dehidroepiandrosteron sülfat, a: androstenedion, T: testosteron. Aynı harfin bulunduğu gruplar arasında istatistik açıdan fark yoktur. 
etinilestradiol/dienogest ve etinilestradiol/siproteron asetatın akne üzerindeki etkileri karşılaştırılmış ve 6 ayın sonunda iki maddenin de antiandrojenik özellikleri dolayısıyla akne üzerinde benzer etkiye sahip olduğu gözlemlenmiştir (19). Bu araştırmada, etinilestradiol-drospirenon ve etinilestradiol-dienogest kombinasyonları hirsutizm üzerinde benzer etki göstermekle beraber ikisinde de herhangi bir yan etkiye rastlanmamıştır.

Polikistik over sendromu (PCOS), multisistem kronik endokrinolojik bir hastalık olmanın ötesinde hirsutizm ve kısırlığın da en yaygın sebebidir (20). Bazı PCOS'lu kısır vakalarda endometriyozis görülmektedir. Bu vakalarda KOK'lar, ağrılı adet ve adet düzensizliğini azaltmak için yaygın olarak kullanııılar. Dienogestin endometriyoz üzerindeki etkisinden dolayı dienogest içeren bir KOK diğer KOK'lardan daha etkili olabilir (20). Araştırmamızda dienogestin hirsutizm tedavisinde drospirenon kadar etkili olduğu görülmüş, PCOS ve endometriyozisli kadınlar üzerinde kullanılmasının ise daha verimli olabileceği gözlemlenmiştir.

\section{Kaynaklar}

1. Batukan C, Muderris II. Efficacy of a new oral contraceptive containing drospirenone and ethinyl estradiol in the long-term treatment of hirsutism. Fertil Steril 2006;85:436-40. [CrossRef]

2. Meier RK. Polycystic Ovary Syndrome. Nurs Clin North Am 2018;53:407-20. [CrossRef]

3. Wiegratzl, Jung-Hoffmann C, Kuhl H. Effect of two oral contraceptives containing ethinylestradiol and gestodene or norgestimate upon androgen parameters and serum binding proteins. Contraception 1995;51:341-6. [CrossRef]

4. Oláh KS. The modern management of hirsutism. Rev Gynaecol Practise 2004;4:211-20. [CrossRef]

5. Murphy A, Cropp CS, Smith BS, Burkman RT, Zacur HA. Effect of low-dose oral contraceptive on gonadotropins, androgens, and sex hormone binding globulin in nonhirsute women. Fertil Steril 1990;53: 35-9.

6. Azziz R. The evaluation and management of hirsutism. Obstet Gynecol 2003;101:995-1007. [CrossRef]

7. Krattenmacher R. Drospirenone: pharmacology and pharmacokinetics of unique progestogen. Contraception 2000;62:29-38. [CrossRef]

8. van Vloten WA, van Haselen CW, van Zuuren EJ, Gerlinger C, Heithecker R. The effect of 2 combined oral contraceptives containing either drospirenone or cyproterone acetate on acne and seborrhea. Cutis 2002;69:2-15.

9. Thorneycroft IH, Gollnick H, Schellschmidt I. Superiority of a combined contraceptive containing drospirenone to a triphasic preparation containing norgestimate in acne treatment. Cutis 2004;74:123-30.

10. G. Oner, Muderris II. "A prospective randomized trial comparing low dose ethinyl estradiol and drospirenone 24/4 combined oral contraceptive versus ethinyl estradiol and drospirenone 21/7 combined oral contraceptive in the treatment of hirsutism", Contraception, 2011; 84; 508-11. [CrossRef]

11. Di Carlo C, Gargano V, Sparice S, Tommaselli GA, Bifulco G, Nappi C. Effects of an oral contraceptive containing estradiol valerate and dienogest on circulating androgen levels and acne in young patients with PCOS: an observational preliminary study. Gynecol Endocrinol, 2013; 29: 1048-50. [CrossRef]
Adet düzensizliği ve hiperandrojenizm PCOS'un ana özellikleridirler (21). Hiperandrojenizm, hiperandrojenemi ve hirsutizm ile karakterizedir (21). Araştırmamızda iki KOK'un da hirsutizm skorunun yanında, serbest ve total testosteron seviyelerini düşürdüğü gözlemlenmiştir. Bu sebeple dionogest içeren bir KOK, drospirenon içeren bir KOK kadar etkilidir ve aynı zamanda PCOS hirsutizm hastaları için yan etki barındırmayan en yeni ilaçtır.

Sonuç olarak; 21/7 günlük 0,03 mg etinilestradiol artı $3 \mathrm{mg}$ drospirenon kombinasyonu ve 21/7-günlük 0,02 mg etinilestradiol artı $3 \mathrm{mg}$ drospirenon kombinasyonu PCOS'lu kadınlardaki hirsutizm üzerinde benzer etkilere sahiptir. İki tedavi rejimi de hirsutizm ve adet düzensizliği üzerinde olumlu sonuçlara yol açmıştır. Ayrıca, dienogest içeren rejim hirsutizm ve endometriyozis hastaları için tercih edilebilir.

\section{Teşekkür}

Yazarlar bütün katılımcılara araştırmaya olan katkılarından dolayı teşekkür eder.

12. Bachmann G, Sulak PJ, Sampson-Landers C, Benda N, Marr J. Efficacy and safety of a low-dose 24-day combined oral contraceptive containing 20 micrograms ethinylestradiol and $3 \mathrm{mg}$ drospirenone. Contraception 2004;70:191-8. [CrossRef]

13. Pearlstein TB, Bachmann GA, Zacur HA, Yonkers KA. Treatment of premenstrual dysphoric disorder with a new drospirenonecontaining oral contraceptive formulation. Contraception 2005;72:414-21. [CrossRef]

14. Koltun W, Lucky AW, Thiboutot D. Efficacy and safety of $3 \mathrm{mg}$ drospirenone/20 mcg ethinylestradiol oral contraceptive administered in 24/4 regimen in the treatment of acne vulgaris: a randomized, double-blind, placebo-controlled trial. Contraception 2008;77: 249-56. [CrossRef]

15. Homburg R. What is polycystic ovarian syndrome? A proposal for a consensus on the definition and diagnosis of polycystic ovarian syndrome. Hum Reprod 2002;17:2495-9. [CrossRef]

16. Barbieri RL. Hyperandrogenic disorders. Clin Obstet Gynecol 1990;33:640-54. [CrossRef]

17. Palombo-Kinne E, Schellschmidt I, Schumacher U, Gräser T. Efficacy of a combined oral contraceptive containing $0,030 \mathrm{mg}$ ethinylestradiol/2mg dienogest for the treatment of papulopustular acne in comparison with placebo and 0,035 mg ethinylestradiol/2 mg cyproterone acetate. Contraception 2009;79: 282-9. [CrossRef]

18. Caruso S, Agnello C, Romano M, Cianci S, Lo Presti L, Malandrino C, et al. Preliminary study on the effect of four-phasic estradiol valerate and dienogest (E2V/DNG) oral contraceptive on the quality of sexual life. J Sex Med 2011;8: 2841-50. [CrossRef]

19. Guida M, Bifulco G, Di Spiezio Sardo A. Review of the safety, efficacy and patient acceptability of the combined dienogest/estradiol valerate contraceptive pill. Int J Womens Health 2010;2: 279-90. [CrossRef]

20. Del Marmol V, Teichmann A, Gertsen K. The role of combined oral contraceptives in the management of acne and sebborhea. Eur J Contracep Reprod Health Care 2004;9:107-24.

21. Regidor PA, Schindler AE. Antiandrogenic and antimineralocorticoid health benefits of $\mathrm{COC}$ containing newer progestogens: dienogest and drospirenone. Oncotarget 2017; 8: 83334-42. [CrossRef] 